MedieKultur | Journal of media and communication research | ISSN 1901-9726

Article - Theme section

\title{
Sensuous proximity in research methods with expert teams, media sports, and esports practices
}

\section{Emma Witkowski}

MedieKultur 2018, 64, 31-51

Published by SMID | Society of Media researchers In Denmark | www.smid.dk

The online version of this text can be found open access at https://tidsskrift.dk/mediekultur

\begin{abstract}
This paper examines epistemological issues in game studies research, specifically exploring qualitative research approaches to networked, expert computer game teams who engage in esports practices. Expert teams deliver their expert practice in part through interembodied sensitivities to sensorial team-based phenomena, which is made across multiple bodies and machines in the process of play. Drawing on fieldwork with World of Warcraft Arena tournament esports teams and research methods orientations from games studies, sensuous ethnography, and sports studies, a position of sensuous proximity in games research is explored and developed as a suite of research guidelines for engaging with esports teams high performance practices. I suggest a research approach that involves differing lenses and stances in the study of embodied team play, and varying scales of sensuous proximity to the layers of expert team practices that augmens the notion of playing research in game studies.
\end{abstract}


Article: Sensuous proximity in research methods with expert teams, media sports ...

\section{Introduction}

The state of esports is one of increasing networked and distributed expert practice as a commercial media production. Esports denotes the institutional practices surrounding organized pro/am digital game tournaments/leagues, and the various routines involved for esports players as expert producers (Hemphill, 2005; Hutchins, 2008; Witkowski, 2012). As a form of competition, many practitioners and institutions have moved closer toward or fully embraced esports as a sports media construct, with expert performances professionally packaged as a competitive sporting event and commodified as a networked media entertainment spectacle. Sports media theorist David Rowe asserts that "Sport is a contemporary medium for performing many tasks and carrying multiple messages and, as such, is increasingly indistinguishable from the sports media" (original emphasis, 2003, p. 2). As they expand into full-blown media sports productions, esports are undergoing rapid socio-structural changes. This transformation of certain digital games and segments of game cultures into a context of media sports challenges some existing concepts, methodologies, and epistemological foundations within the fields of game and media sports studies, prompting a reconsideration of how to study expert practices within networked games as media sports in the making.

As corporatized institutions, both revenue generating and non-revenue generating esports $^{1}$ are developing alongside the rise in the livestreaming of games and the expansion of esports tournaments as international, seasonal variety entertainment mega-events. Within the context of the esports mega-event, qualities of contemporary media sports are echoed with networked computer game players engaging in commercial, professionally-driven institutional frameworks, where the everyday rules, expert participation, and production are modulated by esports-specific policy (national, international, and industrial), commercial rights, and legal frameworks (see Burk, 2013; Taylor, 2012; Witkowski \& Manning, forthcoming). Despite seven-figure viewership numbers reported on single tournaments, increasing mainstream visibility, and traditional sports patronage, esports in the European and American regions still teeter on the periphery-outside of systemic integration across interconnected social structures. Esports remain at the edge of media sports as a networked subcultural behemoth in such regions, unlike sports writ large, where cultural presence is reinforced daily through traditional mainstream institutions (such as family, club activities, educational institutions, and national policy). ${ }^{2}$ Other regions can offer a different glimpse of what cultural embeddedness means for an organized sport/leisure activity.

In South Korea, esports as media sports developed, in part, on a turn-of-the-century initiative to modernize the national telecommunications infrastructure (Jin, 2010). As a national priority, esports were further bolstered through ministerial support, and, with obtainable and affordable broadband Internet cafes, known as PC bangs, quickly spread as a viable small business opportunity, providing cheap and accessible club-like play spaces. Jin and Chee recount the scale and pace of growth in South Korea: PC bangs went 
Article: Sensuous proximity in research methods with expert teams, media sports ...

from 100 sites in 1997 to around 20,000 in 2005 (2008). Fast forward to 2016, and we see how small business owners continue to play a role in the cultivation of esports, with 49 PC bangs receiving certification as official esports facilities or "eSports PC clubs" by the Korea e-Sports Association (KeSPA), which is supported by the Korean Ministry of Culture, Sports and Tourism. ${ }^{3}$ KeSPA's efforts are an attempt to strengthen the esports scenes at all levels, fulfilling the necessary requirements to be approved as an Olympic-ready sporting event (See the Global Association of International Sports Federation's conditions for membership). As South Korea's esports capital, professional teams regularly head to Seoul for a preseason "boot camp" as they attempt to improve team performance by playing against the best on the international level. As this timeline communicates, esports as global media sports are culturally promoted and embedded into civic institutions, policy, and public space on distinctly different regional practices, impacting what it means to participate as a local expert practitioner. With such layers of infrastructure exposed, we can see how virtuosic teamplay is performed beyond the tactics and tempo of a roster of top players. Internationally, participation in and institutional support for esports is expanding from Australia to Denmark, with esports gaining interest and backing from non-endemic businesses and public and cable television, increasingly gaining attention from state and federal bodies as an emerging tourism-creative cultural industry. ${ }^{4}$ Among those in the institutional surge are legacy media sports institutions, which are intensifying their connection with esports on an international scale. Major (namely, male-oriented) media sports institutions are procuring esports players and teams, developing new leagues alongside existing sports federations, and moving into the space as an extension of their brand, products, and services to a youthful, non-sports dedicated and low television consumption audience. These institutions are also advancing their influence through mechanisms of governance (via ownership and major sponsorship), and they are developing the form of production and distribution of esports as media sports (see T. L. Taylor, 2018). These are just some of the developments at the nexus of networked games' progression toward media sports. Such infrastructural flux which enables abrupt modifications in professionalization, endemic values, and performance/production expertise tied to a rapidly expanding youth practice warrants our attention. With esports being solidified as a form of internationally recognized media sports, the specific networked configurations of practice require closer consideration by asking how (mostly) young bodies participate and encounter these modern institutions, which increasingly impact their everyday lives (through direct participation and spectatorship) but provide uncertain benefits.

This article contributes to two pillars of scholarship connected by the fields of media sports and game studies. First, qualitative research methods and epistemological concerns raised in the study of these specific expert practices are considered, in conjunction with a review of the shared socio-material structures between media sports and esports as media sports constructs. By way of sensuous ethnography and phenomenologically 
Article: Sensuous proximity in research methods with expert teams, media sports ...

informed qualitative methods, a suite of conceptual lenses is presented here, reflecting on the sophistication of team practice from the standpoint of esports as networked games and media sports constructs. The fieldwork presented draws on research with World of Warcraft (WoW) players and the expert practices of teams involved in Arena Tournament competitions at local area network (LAN) events (hereon referred to as Arena) (see Figure 1).

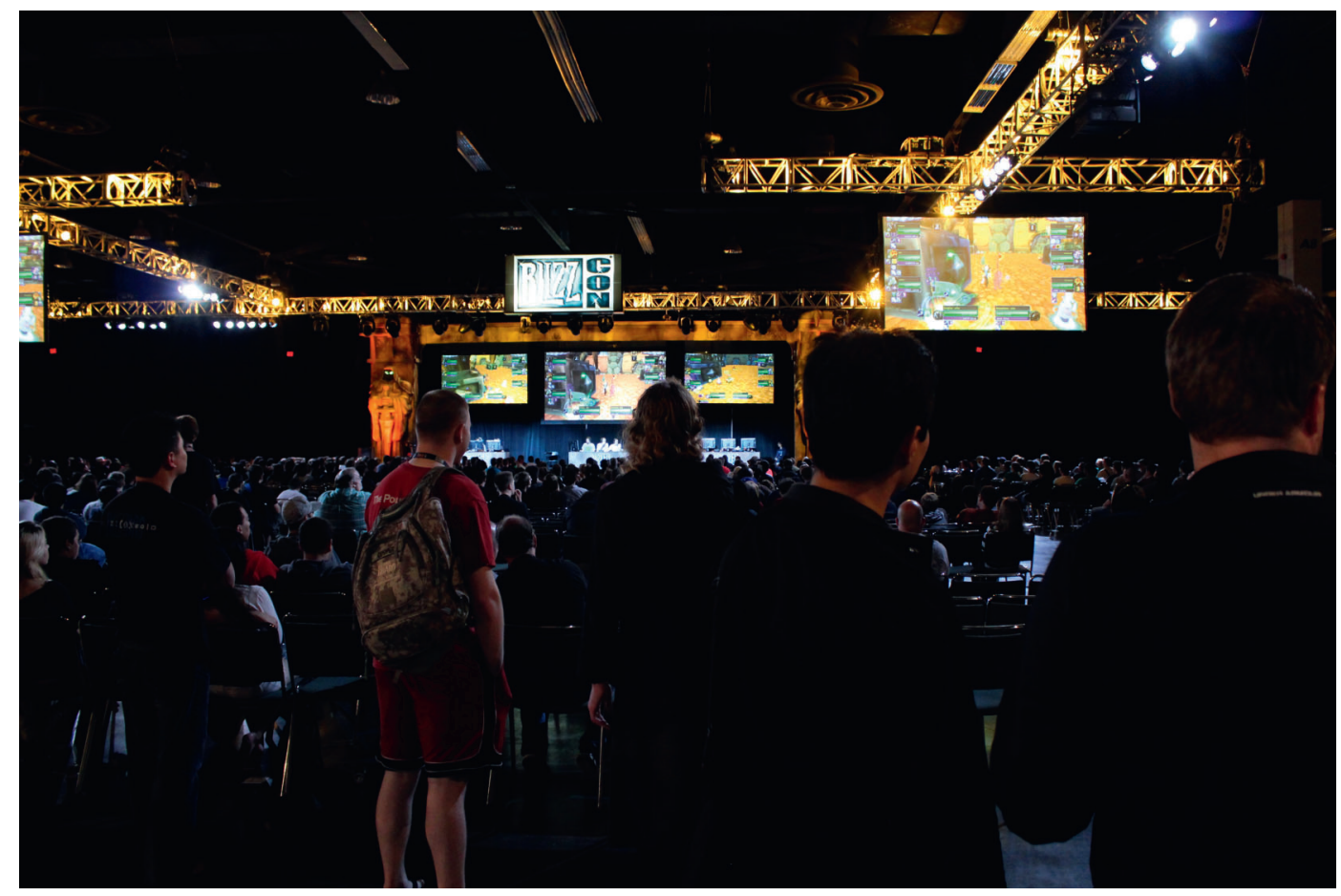

Figure 1. A 3v3 Arena Tournament at BlizzCon 2010, with 27,000 floor tickets available and the possibility to watch livestreamed tournaments on the BlizzCon Virtual Ticket.

\section{Scaling methods and methodologies with networked experts}

As a game form which underwent rapid growth and repositioning as an esport in 2010, the Arena scene is particularly ripe for discussion on how to work within the frame of esports as a qualitative researcher. From 2010 to 2012, I undertook mixed-methods research with top-level WoW teams, which saw my fieldwork move across various fields of gameplay and game cultures. This included 18 months of participant observation with player-versus-environment (PvE) progress raiding guilds, observations/interviews with Arena player-versus-player (PVP) teams at esports LANs, and observations of livestreamed PvP Pro/Am tournaments. Participant observation (as a PvE player) coincided with 
Article: Sensuous proximity in research methods with expert teams, media sports ...

the role of a livestream and LAN event spectator and community participant. My engagement moved across expert sites of practice and development--reading forums frequented by top-level players, watching in-house tournament streams and later on YouTube and Twitch Arena player broadcasts, attending Blizzard conventions, and playing with software from third-party WoW sites used by experts in their practice-while scaling in and out of participatory roles. These roles ranged from a long-term team player in various WoW PvE raiding guilds, to a sideline observer across three seasons of Arena esports events. This study also drew on researcher positionality from elsewhere, drawing on (and intentionally noting) my history as a former professional player and coach in a team sport (basketball).

In developing a sensuous methodology for qualitative research with expert networked teams, my methods were mixed and scaled toward the field and participants, as was my researcher positionality. Researcher positionality ranged from a stance as an expert team sports player, an accustomed WoW team/guild player, and an unfamiliar esports participant, with these roles interwoven throughout the research. Likewise, the methods scaled in proximity to the action-player-as-spectator interviews were conducted during the action of observed team play moments, player-team interviews took place at the event as post-game reflection, and long-form player interviews were organized after the event date, focusing on the lingering issues and practices which had left an impression on the player. Laurel Richardson's notion of crystallization, as a formation of methods, orientations, and perspectives, is highly relevant to this approach of engaging in research with experts involved in team-oriented processes on a scene under professionalization. Crystallization is a research process combining "symmetry and substance with an infinite variety of shapes, substances, transmutations, multidimensionalities, and angles of approach" in the fieldwork, and it transparently reveals a researcher position from somewhere (L. Richardson \& St. Pierre, 2005, p. 963; see also Pearce, 2009). In this study of expert teams, crystallization includes a suite of perspectives, subjectivities, and "touchy-feely" methodsorientations, which zoom in and out of positions of proximity to address the making of this complex expert practice (Paterson, 2009). By scaling in and out of researcher roles and subjectivities and accounting for closeness to and distance from the interplay of team action, this study proposes how sensuously-oriented knowledge of expert teamplay practices and media sports teams can be produced as a non-expert, ringside practitioner, supplementing the game studies stance of "playing research" (Aarseth, 2003).

\section{Media sports socio-material relationship with esports}

The field of media sports offers valuable analytical reflections on sporting practices as an arrangement of what Rowe calls the media sports cultural complex (2004). Jhally's (1984) work in this area highlights key facets in the assemblage of media sports: broadcast technologies, dependency on advertising/sponsorship, dispersed texts (events and discourses), 
Article: Sensuous proximity in research methods with expert teams, media sports ...

and audience making. The analysis of media sports can be more neatly framed as involving "production, textuality, and sociality" (Rowe, 2013, p. 62). Within such a complex, exploring esports, even from the standpoint of team practice, calls for the same sensitivity to the ecology of the game as a networked media production, as these involvements are all in the game and modulate in parallel to the constitutive rules and dominant social forms of participating in an expert competition.

My work with Arena teams was during a time of increasing alignment toward a new form of media sports production - the networked livestream. In 2010, major competitions were mostly niche game broadcasts (BlizzCon livestream, MLG Pro stream, DreamHack, and third-party Arena esports sites, such as Nerdstomper and Arena Junkies). And, by 2011, Twitch was launched as a gameplay-dedicated distribution platform. With the uptake of the new platform, Arena practices shifted significantly around textuality, sociality, and production. The elite level esports ecology saw deeply integrated distribution and monetization/advertising infrastructures develop across networked platforms, shored up on sponsorships/marketing, social media circulation (across events, team brands, and independent personality/skill profiles), and on the production of self-as-brand (see Witkowski, 2019). As the social and technical infrastructure became embedded vertically and extended in scope, both the practice and production of Arena esports was transformed. Livestreaming distribution platforms like Twitch are clearly pivotal to the international growth of esports (See T.L. Taylor's forthcoming book on livestreaming); but what I want to signal here is the broader media ecology beyond the packaged game nudging at the practice of Arena esports, propping up aspects of player-as well as spectator-expertise and everyday team practice (N. Taylor, 2016; T.L. Taylor, 2006). The deep networks involved in producing esports, as media sports, are a reminder that particular forms of gaming expertise are established beyond the performance on a visual digital medium, and are rather completed across dynamic ecosystems supporting and cultivating gameplay and practice (N. Taylor, 2009). This resonates with Hutchins's (2008) work on the relationships among sports, media, and communication, in which he finds the need for a change in syntax, suggesting "It is necessary to think in terms of sport as media (material integration) instead of sport and media (structural interrelation)" (p. 862). Taking a broader stance on the forms and import of the technologies/sports relationship, Butryn (2002) offers a five-part classification of sporting technologies (including self technologies, landscape technologies, implement technologies, rehabilitative technologies, and movement technologies). Two parts stand out in Butryn's classification system as significant to this discussion on material integration-landscape technologies and implement technologies.

Landscape technologies are those technologies which "form the sporting environments in which athletes compete" (p. 112). Sporting environments stretch broadly in their formation from artificial or well-manicured grass and folding roof systems, to white paint marks and uneven asphalt on schoolyard basketball courts - at its simplest, a field (actively) in play. The implemented technologies are demarcated as the "instruments and 
Article: Sensuous proximity in research methods with expert teams, media sports ...

pieces of equipment which are used during the event, and which are generally constituent parts of the contests in which they appear" (ibid.). These include things which are kicked or hurled, or technologies such as bowling balls, sports prosthetics, or tennis racquets. In other words, technologies are integral parts of the basic packaging of a sport and its gameplay in that (the majority of) games would not be the same games without them. Butryn's categories start to describe some of the continuities across esports and media sports, notably the importance placed on constituitive technologies in regulated games. Though, as networked practices, esports have incredibly complex sporting environments. High performance scenes regularly produce compelling new socio-technical and spatial-temporal landscapes of play where we increasingly see audiences synchronously intertwined on performance platforms, revealing new forms of media sports producer/ consumer relationships made across embedded landscape and implement technologies. However, something else must be said regarding the high status of the visual medium.

In speaking of the dominance of the visual over all other senses, Pallasmaa (2005) talks about the hegemony of the visual. He draws our attention to the troubles of such a hierarchy of the senses, maintaining that "[...] our technological culture has ordered and separated the senses [...]. Vision and hearing are now the privileged sociable senses, whereas the other three are considered as archaic sensory remnants with a merely private function" (p. 16). The visual/representative casing is just one layer of engagement in the process of play, and as Pallasmaa continues, the other senses "[...] are usually suppressed by the code of culture" (ibid). This supports the argument to "play research," i.e., to be a player of the game one is studying and to embody the processes of gameplay and game cultures (Aarseth, 2003). While esports engage a visual digital medium as one of their operational characteristics, Arena players execute and express their expertise as a multimodal performance. Body memory is sensuous, and often not revealed in talk or just from spectators of play (Allen-Collinson, 2012; Richardson \& Keogh, 2017; Witkowski, 2012). From a phenomenological perspective, "Sight and touch are able to communicate with each other, to provide confirmations (or contradictions) of each other, because they are the senses of one and the same subject operating simultaneously, within one and the same world" (Grosz, 1994, p. 99). Lag, for example, represents how the visual digital medium of games is also an integrally felt field of play (Consalvo, 2008; Dourish, 2004). As one virtuoso high performance Arena player expressed it, "It's a lot easier to feel lag than it is to see it." His touch gives texture to lag; he feels the playing field.

Such tacit layers of expert team play are explored here, with attention given to the embodied team practices made beyond references to the visual/digital medium, and, while central to playing games, these forms address only part of the story of expert team practice (Butryn, 2002). Following the work of sports phenomenologists (Allen-Collinson \& Hockey, 2011; Arnold, 1979), three interlocked alignments guided this research methodology with expert teams. Each alignment asks for an explicit consideration of the dynamic 
Article: Sensuous proximity in research methods with expert teams, media sports ...

relations involved in team practice, and to locate the sensuous proximity of the researcher to the practice itself.

These orientations include intercorporeality as a focus and orientation for the researcher toward the action a single team creates together, where it is described as a body in practice being experienced by other teammates (with a similar suite of goals), but also by "ourselves" (Sokolowski, 2000, p. 154). In this sense, intercorporeality refers to the intimate experiences of a performing team.

A second orientation is toward inter-team embodiment, which considers relationality toward performers on other teams or, better said, recognizing, negotiating, and orienting oneself and the team toward the intercorporeality of the opponent squad (Allen-Collinson \& Hockey, 2011, p. 342). Inter-team embodiment prompts the team researcher to consider expert performance in terms of reversibility (Merleau-Ponty, 1968), where, as a body, we touch and are touched, see and are seen in our actions. This is best illustrated when teams create complex pressures, such as the reversibility of actions between a player and the individual defender, but also between an entire team working in offense (attacking) the intercorporeality of the cohesive team on defense, who are defending against space, possible actions, and opponent goals.

The last orientation draws on the notion of team interplay: the labor between opponents, technologies, and spectators, and the latticework of felt "auxiliaries" (all mediating socio-material peripherals) in flux together (Allen-Collinson \& Hockey, 2011). Interplay is a substrata category drawing together a holistic expression on the core acts and actions which formulate networked team practices. When I talk of interplay from the perspective of Arena players, it must be noted that it draws on an assemblage of observations, interviews, and moments over time. Only one or two specific player/team experiences gain clear articulation at any given time when talking about interplay (i.e., team play as impacted by tournament rules on peripherals, such as when an unfamiliar keyboard layout alters the practiced touch of a player and the overall timing of the team), highlighting the continued work to be done on methods, methodologies, and forms for articulating non-representational, complex practices. As Law reminds us, "[...] events and processes are not simply complex in the sense that they are technically difficult to grasp [... ] Rather, they are also complex because they necessarily exceed our capacity to know them" (original emphasis, Law, 2004, p. 6).

Allen-Collinson and Hockey's (2011) call for future sports researchers to chart "embodied, embodied via auxiliaries, and inter-embodiments" in their investigations on the interrelationships of experience and structure involved in sporting touch in team sports has been taken on (p. 342). The approach I present here develops their tri-level catorgorisation with attention to digital play as always involving a multiplex of networked landscape and implement "auxiliaries" that are entangled with expert team practice. As an approach to exploring sensorial phenomena as a central aspect to team expertise, the categories of intercorporeality, inter-team embodiments, and interplay orient the researcher to the 
Article: Sensuous proximity in research methods with expert teams, media sports ...

various forms and layers involved in producing expertise in networked teams, where the social and material are complexly pressuring the lived teamplay moment. With attention to the specifics of multi-modal expertise, alongside the shifting scales and angles of researcher closeness in studying complex high-level teamplay, the researcher is ultimately moved beyond the basic encounter of playing research to a stance of playing multiple positions and being accountable for them.

\section{On playing research}

One of most-cited game study articles is "Playing Research" (Aarseth, 2003) which is notable for its introductory reflections on game research methods and its emphasis on researcher involvement in the study of play itself. In 2003, Aarseth's work delivered a timely response to those conducting cursory investigations concerning computer gameplay. As an agenda, playing research encourages analytical care in the study of complex processes, but also attentiveness to the playing practice of the researcher. Thus, we are led to ask: Is the playing researcher involved in explorative or analytical play? The non-player as game researcher is also promted to consider the resources used (are they consistent with the research question?), and the value placed on secondary materials (e.g., game designer interviews, commercial game reviews, or player walk-throughs). The field of game studies remains heavily influenced by the straightforward play-strata framework, where the strata are briefly outlined as a range of researcher-as-player engagements, from superficial play (tinkering with the game) up through seven tiers culminating at expert/ innovative play (in ascending experiential order: superficial, light play, partial completion, total completion (not attainable in all games), repeated play, expert play, and, the last stage, innovative play).

In Hine's ongoing work on virtual methods, she reflects, "In the moments of innovation and anxiety which surround the research methods there are opportunities for reflexivity" (2005, p. 9). Esports as media sports prompt such an opportunity. Considering my playing research positionality in WoW, my playing strata ranged from light play (in PVP) to repeated play (with PVE progress raiding guilds and practiced pick-up-group team play in WoW). At times, I experienced mastery of a space as a form of repeated play (such as a heavily repeated instance) and was engaged in a localized form of repeated/ expert play, but only within that specific arrangement of play, not as an ongoing practice. ${ }^{5}$ Throughout the playing research process, Aarseth's (2003) final two levels of play, "expert play" and "innovative play," were never reached. These were precisely the strata of players I was studying. Aarseth goes on to say, "If we comment on games or use games in our cultural and aesthetic analysis, we should play those games, to such an extent that the weight we put on our examples at least match the strata we reach in our play" (2003, p. 7). While I support the premise of "playing research," an equivalent stratum in research on expert team practice is a fraught orientation, particularly at the expert/innovation levels 
Article: Sensuous proximity in research methods with expert teams, media sports ...

of engagement (Arnason, 2011; see also Boellstorff et al.'s (2012) discussion on participation from the standpoint of ethnography in virtual worlds). While Aarseth also highlights the need for different scales and angles across research forms (including non-play), it is feminist perspectives on research methodologies that offer a range of complications involved in "reaching" the expert position. Most notable here is the issue of corporeal identity and researcher positionality, which challenges the operationalization of a playing research strata for all, and particularly so for research within specific team-based media sports where collaborator/participant engagement is central to qualitative involvement (Brownell, 2006; Pearce, 2009; Visweswaran, 1994). Considering the inter-team plurality of perception within any team practice, reflexivity on the researcher position itself is a vital part of the production of team-based media sports knowledge.

In the following research on expert team practices within networked media sports, I have drawn upon another "researcher as player" position, that of the sensuous researcher (de Garis, 1999). This position involves sensuous proximity to the player-practices and multiple sites involved in the study, and encourages a standpoint of nearness, emphasizing multi-modal attention to complex forms of practice (intercorporeal, inter-team embodiments, and interplay), as well as acknowledgement of this research practice as a cooperative endevour involving different bodies and machines.

Working toward the production of sensuousness in sports research, de Garis (1999) draws on his experience as a former professional wrestler who was observed in his athletic practice by another ethnographer. Drawing on his long-term experience in professional sports (and evaluation of himself outside of it through another's text), de Garis emphasizes an alternative to some equivalent strata in "playing research": that getting into the ring need not entail "getting in the ring" (p. 72). That is, the researcher does not require "equal" playing experience as the object of intercorporeal study (see also Waquant, 2004).

In his reading of the ethnography produced by Sharon Mazur - the researcher and a non-wrestler whose fieldwork was conducted at de Garis's gym-he notes the absence of a sensuous account of the practice, which ultimately reduced the holistic quality of her study through her distance from the (performative) field. Her research position took in the scene entirely from outside of the ring. Yet, de Garis is less concerned here with Haraway's god-trick, "seeing everything from nowhere," where general knowledge claims are made without accounting for researcher positionality (see Haraway, 1991, p. 189). Rather, he concentrates on the limits of what might be called "sense-less" research. Taking a sidelined position, de Garis argues, results in lost body work and tacit processes involved in the shaping of a practice. In taking on this intercorporeal orientation to fieldwork, research on expert team practices calls for getting near to, and a feel for, the reversibility of bodies and auxiliaries in action together across multi-sited fields of play. When bodies and technologies are on stage performing as practiced teams, subtle cues, such as touch, hesitation, intimacy, or the unseen pressure points engaged in the moment of the activity, are significant pieces of the experience which are accessible to the research/researcher 
Article: Sensuous proximity in research methods with expert teams, media sports ...

at some level, though not necessarily through expert play. By bringing the researcher (in this case, Mazur) into a training session, de Garis argues a sensory attunement toward the practice of professional wrestling, and the nuances of expert participation would then, as a result, be bolstered. By training alongside him, he argues, Mazur would develop some of the crucial body knowledge to be able to sense Geertz's distinction between a wink and a blink (1973, p. 6), rendered in wrestling as subtle and strategic inter-embodied practices in the shaping of the performance.

Taking a researcher position of sensuous proximity is an orientation which encourages scaling in and out of the socio-technical arrangements and processes of play and considering the extent of embodied knowledge of such scaled positions. Mirroring aspects of Aaresth's play strata (recognizing the level of play one has been involved in-from light play to expert/innovative play), sensuous proximity rests on two supporting foundations, that structural likeness across game cultures and landscapes and implement technologies are involved (such as playing within the same game world, having experience in familiar competitive tournament structures, and playing with established as well as newly established teams). Also, similarities in socio-material integration are achieved (for example, using the same third-party add-ons, participating in livestreams, using third-party voice communications, and engaging in the forum sites regularly visited by participants and game developer/organizers), without deferring to an instrumental catch-all or "playing research" position of level equivalence.

My own long-term play in team sports and in WoW PvE exemplify de Garis' remark on researcher positionality (that getting into the ring need not entail "getting in the ring" (p. 72)). My participation in WoW involved structural and embodied socio-material likenesses, and acknowledged the researcher body as a "tool to gain insights into research subjects and their geographies" (Longhurst et al., 2008). Importantly, through my participation across varying field-sites and gradiated closeness to playing research, different scales, angles, and positions of sensuous proximity to the practice of Arena LAN participants was accounted for. The sensuous proximity to Arena players was clearly expressed, for example, through similar experiences, including:

- Practice deterioration and loss of a silky touch with tools and game rules from going "offline" over the summer,

- Encountering new patches and the time required to get acquainted with them across a team (remapping the keyboard, seeing how new abilities "work" with and against others),

- Negotiating local lag and dealing with technologies/bodies going "wild" mid-play (such as the W-key flying off my laptop in the middle of a boss fight, and having to play on),

- Knowing the personalized push-pull of player-referee relationships and the intensity that international tournaments place on local practice, 
- Managing the change from pre-game plans to on-the-fly actions as games unfurl and planned performances diversify, and

- Handling of body pressures before, during, and after a performance, both individually and as a team.

These were all parts of performing expert play, and they express how any small amount of touch and feel "in the ring" is valuable in communicating the field in process, dialogue, and text. In other words, "becoming" a full-blown actor (a skilled wrestler or high performance player) is a nonessential demand; rather, through participating across a suite of infrastructural (socio-material) techniques, timings, and arrangements of teamplay, the researcher can gain some closeness to familiar layers of actions made by bodies and machines, tacit pressures, body feel, movement, and inter-team embodiments, ultimately offering a more sensuous account or, more fittingly, a less sense-less position of study.

\section{Toward scales of sensuous proximity with expert teams}

Within the fields of game and media/sports studies, little systemic research attention has been given to the relational (inter-team) embodiments and professional tensions materializing in esports as networked media sports (Hockey \& Allen-Collinson, 2007, p. 127; Hughson \& Inglis, 2002). ${ }^{6}$ Therefore, it is relevant to riff on Hockey and Allen-Collinson's questions on traditional sporting bodies-How do expert team/players experience their contact sport and make sense of the field? How are they challenged to express the phenomenology (the combined "touchy-feely" parts) of expert play in embodied, mediated space? How are esports teams and machines getting "in-synch" through avatar representation and non-representational actions? and What are movement inflections that matter for networked teams, and how are they interpreted in the interplay of the opposition? (2007, p. 127). A sensuous study of the lived and bodily experiences of expert teams is undeniably a challenging and time-consuming task. Talking to teams, playing with machines, and feeling aspects of interplay from different scales and angles are the first steps to developing more acute research on how team play in esports is achieved by many bodies and technologies in action (Chen, 2009). Addressing sensory work is, as such, essential in recognizing the substance of teamplay and the modalities involved in cultivating networked expertise in esports as media sports.

In this study, research themes developed within the dialogues and on-the-scene observations of the collaborators in the field, as well as through player-as-audience positions as a concurrent form of the "observer's observer," where collaborators "report events not directly observed by the field worker" (Zelditch, 1962, pp. 570-571). In the simultaneous form of the observer's observer, I would watch games from the audience with an expert player, be in dialogue about the plays, and talk through important on-stage happenings which could be followed up post-game by watching broadcast gameplay sequences- 
with those who produced the play itself. The observer's observer offered further layers of expert perspective, meaning, and context to the practice. Perhaps Zelditch's most valid point here for thinking about complex interplay is that "a single observer cannot be everywhere at the same time, nor can he be 'everywhere' in time, for that matter he has not been in S forever [Where $S$ refers to a social system under inquiry], and will not be there indefinitely that, inevitably, something happens that he has not seen, cannot see, or will not see" (p. 572). To extend this point, a single player in-game perspective, or solely from the stands, represents an abridged perspective of the inter-team sensorium.

Conversations with participants were often ad hoc, but ongoing in my sensuous study of team play. I hung out on the scene for endless hours and watched/talked with and about others playing the game well (and poorly) together (see also Taylor, 2012). During these ad hoc encounters, core issues were frequently repeated over time across a scene, while instructive points and newfound topics developed through player-audience dialogue (playing and seeing the game space expertly by digetic audio effects was one such topic). Our diverse sensuous attentions to expert team play arose in situ. As such, the intended meaning or, rather, the multiplicity and nuance in player experience and team expressions were attended to in an ongoing process of "data collection", interpretation, and thematic development.

As noted by Clifford and Marcus (1986), the research process is holistic, not segregated (with fieldwork "over here" and writing/analysis "over there"), and expert players as spectators and teammates were involved in the foundational process of making their play on paper (this is not any argument for authenticity, the final writings are my desk edits and, as such, present only a partial perspective which grew out of the fields in play.)

The following vignette offers a small snippet, a synthesized spatio-temporal moment, which provides an insight into the nexus of playing researcher (playing familiarity with gameplay and game mechanics in the game), teamwork sensitivity (intimate knowledge of teamplay and coordinated timing in the game, and in situ dialogue with an observant expert), and scaling in and out of closeness to the practice (through different methods and closeness to production and sociality). In this scene, I am sitting alongside an observer's observer at the tournament, as we watch, talk about, and make sense of a seemingly "unseen" play as it unfolds before us on-stage. This speaks to the intercorporeality, interteam embodiment, and interplay which occurs at the expert level of play.

\section{The invisible kill}

An expert player's intentionality and inter-team sensorium are focused on the constant process of moving and meaning making: processing distance between opponents, LOSing (referring to line-of-sight: unobstructed positioning on the map between a player and teammate/opponent enabling ranged abilities/spells on a target), lag, cool-downs used, player actions in-the-room, crowd control, and the range of sudden or unarticulated moments inflecting on play. At the BlizzCon finals, Dewey grabs the seat beside me. He's 
Article: Sensuous proximity in research methods with expert teams, media sports ...

a team franchise player on the Arena scene and seems to enjoy "talking shop." As we watch an enthusiastically applauded tactical opening, Dewey explains how the best plans are always contingent on the expressive field, but also notes how in-game locations are realized:

Dewey: Whatever they [the opposition] do, you instantly realise what they're doing because of what they're doing.

Me: But, you've also already laid out your opener, so does it become too late...

Dewey: No. This game is about instant decisions. Yeah, they saw the Rogue cloak [referring to a team we are watching compete, the Rogue uses his "cloak" spell—which makes him suddenly invisible to the opponents]. Latei played defensive instantly. Everything was just instant decision-making. So, no matter what strat [strategy] you wind up, you could have it typed out, tattooed it on your arm. If they're doing something crazy, you have to change.

Me: You say they saw him cloak? Does that get communicated?

Dewey: No, everyone knows it.

Me: How?

Dewey: It's noise, it's graphics, icons...

Desirable tactics are chosen with reference to the environment and opposition, including map and lag expectations, as well as match-up histories, opponent preferences, and how things are "functioning" on the day, though such tactics can be picked apart not only on the visible field, but through the sound (each spell has an audible tune) and the negative space (such as the suddenly invisible Rogue). Latei recognized not only the gap, but, in that moment of invisibility, he also sensed where the Rogue would likely attack from. His extensive gaming history worked into this fast-paced inter-team sense-work, creating this moment of expert practice. Latei's sensing here was described as "awesome" on the scene (by the audience, other players, and shoutcasters). The praise is tied to "blindly" sensing the location through expert embodiment and inter-team practice, by piecing together what was missing on the field and sensing where that invisible player might be found.

As suggested through the vignette, with each move an Arena player makes, the opponents (and, indeed, teammates) are reacting to the changing locations, gaps, soundscape, and momentary player-formation landscapes, in which every movement is crucial to the endgame state. And, as players note, successful and "synergistic" team play is created through inter-team adaptability: being able to see, hear, sense, and adjust to the changing play states-those fast-changing moments in the game-together. In a more provocative phenomenological reading, Hughson and Inglis (2002), drawing on a Merleau-Pontian phenomenology, articulate on the expert play of football that:

[...] for the player-body-subject, the spatial elements of the field, such as the goal and penalty areas, and his or her subject-bodily dispositions are, in a sense, of the same substance. The spatial contours of the field and the dispositions of the player are mutually implicated 
Article: Sensuous proximity in research methods with expert teams, media sports ...

elements of an indivisible whole. One may even go as far as to say that, after a fashion, the player and the field are literally the same thing (original emphasis, pp. 7-8).

While Hughson and Inglis speak from individual experience here, this can be adapted for the Arena LAN teams to highlight the joint efforts on the playing field where the "elements of an indivisible whole" include, players, teams, opponents, technologies, and the field of play as "the same substance" (pp. 7-8).

It is in such unquantifiable and vibrant team moments of collective spatio-temporal execution that a secure indication of team expertise is found. The team sensorium surrounding this invisible play was made through expert practice, but, just as importantly, it was made in an absence, through the invisible player (as represented as not being there) but also through non-representational aspects of teamwork and future team-state perceptions. Grosz (1994) can offer us another layer to this form of corporeality, arguing through the example of a visually not present, but "felt" phantom limb, that "... our experiences are organized not by real objects and relations but by the expectations and meanings objects have for the body's movement and capacities" (p. 89).

Seeing, the visual, is entrenched as the foremost Western sense (Pallasmaa, 2005). However, seeing is only one plane of a game in practice - touch, sound, and the interplay (among many bodies and many technologies) and the texture thereof are also key components in the sensation of the field of play. These under-the-skin sensations are often inaccessible, distinctly foreign atmospheres to the non-playing researcher, particularly when considering an expert's practice. A stock car driver, for example, avoids demarcating between her body, an awareness of the tyres on the track, and the visual displays of either the tarmac road stretching out before her or the digital gauges at her fingertips. Likewise, playing in a visual digital medium does not entail "looking twice" to actively see what is real and what is virtual (Hockey \& Allen-Collinson, 2007, p. 121). High performance players forgo talking and performing in this dissected manner. For them, it is one location, one field of play accomplished through an assemblage of components-in game, on field, and through practice-for the practice to exist as such (T. L. Taylor, 2009).

In the following vignette, Team Nosh-Up formulates another perspective on the sensuous configurations of team practice, articulating how expertise is weakened on a newly established team and in non-practiced relationships, and expressing their attunement to the sensuous aspects of team expertise.

\section{Personalization of team expertise}

For high performance teams, "pre-choreographed" plays are only guidelines. At this level of participation, no victory is assured through instrumental practice or, as a top player reassures us, no one should expect to win on paper. Expert teams need to find their footing together as a holistic unit. During a post-game team interview with "Atlas," "Plasma," and a trial player "Rookie," we spoke about playing field awareness. In the following extended interview excerpt, we discuss the significance of being sensitive, 
Article: Sensuous proximity in research methods with expert teams, media sports ...

responsive to, and "knowing" teammates-how they move, their cadence, and their mapspecific proclivities.

\begin{abstract}
Atlas: It's so [player emphasizes word] huge because, since he's the healer a lot is dependent upon him, and it's a lot to get used to. Like we just lost a game earlier in the morning because my position didn't correspond with his position very well, and it cost us the game instantly. So, it's just such a big thing to get used to. LOSing, player movement, and the way they rotate [spell or ability] and stuff like that.

Me: So how do you practice that?

Atlas: It's just games. Like, I can tell everything Plasma is going to do because I've played with him for so long. When he starts going one way I know exactly where he's going to come out after, so it just comes after time.

Me: Is that the same from your end [asking Rookie]?

Rookie: I don't know their synergy, like I don't know how or how well they play together. I know how my old partners played, but when I'm playing with them [pointing to his new teammates] I have to, I'm expecting certain things, and I'm not really sure that things are going to come out the way I expect it to. So, like, if he's going to do one thing, is the other one going to do the following? Because I don't understand their synergy like I did my old team.
\end{abstract}

The substance of team synergy, resulting in expert performance, is attained through sensitivity to collectively practised bodies and not needing to look twice, or look at all, for the team to play well. ${ }^{8}$ Expert play hinges on the practiced perception of likely performances and "angles" created between and among players, not only via a composition of synergistic class (in-game) abilities but, more discreetly and non-verbally via the interplay of how players hold, take, and flee their field positioning across the dynamic bodies in play.

In terms of how shared systems of knowledge are generated between researchers and the collaborators in the field, a concluding point on researcher positionalities, fields, and expertise must be considered. Harper (2010), in his exploration of the Evolution fighting (video) game tournament scene, chose to engage in deliberate deception, explaining that he needed to "convey a sense of uncertainty" (p. 63) during his interviews with players in order to keep his own "gamer" and "in the know" orientation under cover. Harper was a practiced player, but his wise, context specific, choice to position himself as an amateur allowed the field participants exclusively to take on the role of expert and embodied knowledge holder. My position worked from a different standpoint, from one of expressed sensuous proximity. I communicated that I had experienced the pressures of team play, the feel of expert competition, playing toward bodies (teammates and opponents) in not yet inhabited space, the tinkering of play against adjudicators, the weighty changes of rules altering inter-embodied team practice, and on-the-fly adjustments to acting up technologies (and officials) from a sensuous proximity to expert teams drawn from elsewhere. Those researcher subjectivities presented to the research participants 
combined my long-term team play in WoW PvE instances - a feel of play from within a game, though not the same game form - and long-term expert teamplay on pro/am basketball teams. In conveying a sense of familiarity of the inter-team sensorium, through a fusion of dialogue on high performance team sports practice and WoW group play, more broadly, we created a comfort zone together for sensuous talk about teamplay experience and the grit involved in doingnetworked high performance team play well together (Pink, 2007). Though cues, such as gender and age, are certainly at work in my researcher position (as was the case in Harper's shrewd choice in presenting as an amateur player), the visual presence of a mature woman on the scene was perhaps perplexing enough for players not to be threatened in such expressive and sensitive conversations. This juxtaposition (of woman, mature, practiced teammate, WoW player, and [for them] outsider) was a generative practice and position at live events - I was a non-threatening and interested (though "just temporary") local on the scene with whom the experiences of team play could be shared. ${ }^{9}$ This is a privileged position. As researchers, we all have different enabling practices and possible plays which bring other perspectives and angles on the making of a practice: these should be accounted for rather than obscured in writing or, even more problematically, omitted all together. Or, as Richardson and St. Pierre's approach to ethnographic research suggests, a productive stance might include varying angles and scales of fieldwork participation in developing an always already partial perspective, as there is no assumption of a fixed point/object of study-only possible angles of approach (2005, p. 693). Importance is placed on transparency. It is essential in recognizing the familiarity of a practice or aspects of practices, and articulating subjectivities in the field, such as asking who can attain such positions, what it means to actively support other research subjectivities in the field (and within institutional frameworks), and what such positionalities mean for the body of research which engages a subject and produces knowledge.

\section{Conclusion}

As a contemporary media sports cultural complex, esports represent a vertically embedded (across commercial platforms) form of networked media sports. Within this complex, players, fans, and institutions have deeply integrated socio-technical relationships and, as such, there are emerging complexities to consider for both game and media sports scholars. Ongoing issues in the professionalization of esports as media sports call for explorations on how integrity (from match-fixing to fair play) is established across complex, mediated, esports spaces (see N. Taylor, 2012). These issues also question how diversity is cultivated in expert competition-from tacit team recruitment practices to explicit institutional structures around participation (see Anykey.org), or how independent esports celebrity and livestreaming lifestyles challenge the various forms and values of organized teamplay (Witkowski, 2019). Within all these areas, expert players hold valuable embod- 
ied knowledge on the stakes involved both for their personal/inter-team practice and for the fitness of the scene of play itself. In this growing sector, high performance players take up a position as networked media sports experts and as meaning-makers with an international (spectatorship) and institutional (insider) reach. ${ }^{10}$ These players and teams are "exemplars of play" (Hemphill, 2005), embodying the impacts of socio-structural change, and their everyday actions have bearings on subsequent cohorts of players/producers. Sensuous proximity, as a researcher positioned within game research, is, as such, a significant stance in this research space. In After Method: Mess in Social Science Research, Law argues that "Almost certainly, we will need to think hard about our relations with whatever it is we know, and ask how far the process of knowing it also brings it into being" (p. 3). Law's position articulates partial connections and prompts an interrogation of the process of knowing. There are spatio-temporal fragilities in teamwork with and against others, and further vulnerabilities are found on networked foundations within a developing scene of play. Some of these coordinations are visible, other plays are fleeting and indiscernible moments which pass the etic observer by. The position of sensuous proximity to expert team practice integrates different degrees of closeness to play, and it explores how playing research, researcher positionality, and feeling toward expertise in media sports team practices matter in game studies. But this is just an opening stance, and, certainly, not all researchers can access sensuous proximity to their field sites. Sociomaterial positionality alone poses a multitude of barriers, such as gender, age, ability, ethnicity, and language, for researchers. Accordingly, this position on sensuous proximity is a guide, a toolkit to think through what closeness means for the holistic exploration of a particular research situation, and on how researcher positionality feeds the study itself. As relationships progress across game/sports institutions and play cultures, there are other productive methods, concepts, and dialogues to explore-challenges to wrangle with at the supposed seams of these networked media sports practices.

\section{References}

Allen-Collinson, J. (2012). Feminist phenomenology and the woman in the running body. In I. Martínková, \& J. Parry (Eds.), Phenomenological approaches to sport. New York: Routledge.

Allen-Collinson, J., \& Hockey, J. (2011). Feeling the way: Notes toward a haptic phenomenology of distance running and scuba diving. International Review for the Sociology of Sport, 46(3), 330-345.

Arnason, L. (2011). New media, new research methods: Current approaches to research in the virtual world. Media International Australia, 138, 98-111. DOI: 10.1177/1329878X1113800112

Arnold, P. J. (1979). Meaning in movement, sport, and physical education. London: Heinemann Education. Boellstorff, T., Nardi, B., Pearce, C., et al. (2012). Ethnography and virtual worlds: A handbook of methods. New Jersey: Princeton University Press.

Brownell, S. (2006). Sport ethnography: A personal account. In D. Hobbs, \& R. Wright (Eds.), The SAGE handbook of fieldwork. Thousand Oaks: SAGE. 
Burk, D. (2013). Owning e-Sports: Proprietary rights in professional computer gaming. University of Pennsylvania Law Review, 161, 1535-1578.

Butryn, T. (2002). Cyborg horizons: Sport and the ethics of self-technologization. In A. Miah, \& S. Eassom (Eds.), Sport technology: History, philosophy, and policy (pp. 111-134). Oxford: Elsevier Science.

Chen, M. (2009). Communication, coordination, and camaraderie in World of Warcraft. Games and Culture, 4(1), 47-73. DOI: 10.1177/1555412008325478

Clifford, J., \& Marcus, G. (Eds.). (1986). Writing culture. The poetics and politics of ethnography. Berkeley: University of California Press.

Consalvo, M. (2008). Lag, lingo \& language: Theorizing noise in online games. In M. Wolf, \& B. Perron (Eds.), The video game theory reader 2 (pp. 295-312). New York: Routledge.

De Garis, L. (1999). Experiments in pro wrestling: Toward a performative and sensuous sport ethnography. Sociology of Sport Journal, 16, 65-74. DOI: 10.1123/ssj.16.1.65

Dourish, P. (2004). Where the action is: The foundations of embodied interaction. Cambridge, MA: MIT Press.

Geertz, C. (1973). The Interpretation of cultures. New York: Basic Books.

Grosz, E. (1994). Volatile bodies: Toward a corporeal feminism. Bloomington, IN: Indiana University Press.

Haraway, D. (1991). Simians, cyborgs, and women: The reinvention of nature. London: Free Associations Books.

Harper, T. (2010). The art of war: Fighting games, performativity, and social game play. (Doctoral dissertation). Ohio University, USA.

Hemphill, D. (2005). Cybersport. Journal of the Philosophy of Sport, 32(2), 195-207. DOI: 10.1080/00948705.2005.9714682

Hine, C. (2005). Virtual methods and the sociology of cyber-social-scientific knowledge. In C. Hine (Ed.), Virtual methods: Issues in social research on the Internet (pp.1-16). Oxford: Berg.

Hockey, J., \& Allen-Collinson, J. (2007). Grasping the phenomenology of sporting bodies. International Review for the Sociology of Sport, 42(2), 115-131. DOI: 10.1177/1012690207084747

Hughson, J., \& Inglis, D. (2002). Inside the beautiful game: Toward a Merleau-Pontian phenomenology of soccer play. Journal of the Philosophy of Sport, XXIX, 1-15. DOI: 10.1080/00948705.2002.9714619

Hutchins, B. (2008). Signs of meta-change in second modernity: The growth of e-sport and the World Cyber Games. New Media \& Society, 10(6), 851-869. DOI: 10.1177/1461444808096248

Jhally, S. (1984). The spectacle of accumulation: Material and cultural factors in the evolution of the sports/ media complex. Insurgent Sociologist, 12(3), 41-57.

Jin, D.Y. (2010). Korea's online gaming empire. Cambridge, MA: MIT Press.

Jin, D.Y., \& Chee, F. (2008). Age of new media empires: A critical interpretation of the Korean online game industry. Games and Culture 3(38), 38-58. DOI: 10.1177/1555412007309528

Law, J. (2004). After method: Mess in social science research. New York: Routledge.

Longhurst, R., Ho, E., \& Johnston, L. (2008). Using "the body" as an "instrument of research": Kimch'i and pavlova. Area, 40(2), 208-217. DOI: 10.1111/j.1475-4762.2008.00805.x

Merleau-Ponty, M. (1962). The phenomenology of perception, trans. C. Smith. London: Routledge.

Merleau-Ponty, M. (1968). The visible and the invisible, trans. A. Lingis, Evanston: Northwestern University Press.

Pallasmaa, J. (2005). The eyes of the skin: Architecture and the senses. Chichester: Wiley Academic Publishers.

Paterson, M. (2009). Haptic geographies: Ethnography, haptic knowledges and sensuous dispositions. Progress in Human Geography 33(6), 766-788. DOI: 10.1177/0309132509103155 
Article: Sensuous proximity in research methods with expert teams, media sports ...

Pearce, C. (2009). Communities of play: Emergent cultures in multiplayer games and virtual worlds.

Cambridge, MA: MIT Press.

Pink, S. (2007). Doing visual ethnography. London: Sage.

Richardson, L., \& St. Pierre, E. A. (2005). Writing: A method of inquiry. In N.K. Denzin, \& Y.S. Lincoln (Eds.),

The SAGE handbook of qualitative research (pp. 959-978). Thousand Oaks: SAGE.

Richardson, I., \& Keogh, B. (2017). Mobile media matters: The ethnography and phenomenology of itinerant interfaces. In L. Hjorth, H. Horst, A. Galloway, et al. (Eds.), The Routledge companion to digital ethnography (pp. 211-220). New York: Routledge.

Rowe, D. (2003). Sport, culture \& media: The unruly trinity. UK: McGraw-Hill Education.

Rowe, D. (2013). The sport/media complex: Formation, flowering, and future. In D.L. Andrews, \& B. Carrington (Eds.), A companion to sport (Blackwell companions in cultural studies). (pp. 61-77). Chichester, West Sussex: Wiley Blackwell.

Sokolowski, R. (2000). Introduction to phenomenology. Cambridge, UK: Cambridge University Press.

Taylor, N. (2009). Power play: Digital gaming goes pro. (Doctoral dissertation). York University, Toronto, Canada.

Taylor, N. (2016). Now You're Playing With Audience Power. Critical Studies in Media Communication 33(4), 293-307.Taylor, T.L. (2006). Play between worlds. Cambridge, MA: MIT Press.

Taylor, T.L. (2009). The assemblage of play. Games and Culture, 4(4), 331-339.

Taylor, T.L. (2012). Raising the stakes: The rise of professional computer gaming. Cambridge, MA: MIT Press.

Taylor, T.L. (2018). Watch me play: Twitch and the rise of game live streaming. Princeton: Princeton University Press.

Visweswaran, K. (1994). Fictions of feminist ethnography. Minneapolis: University of Minnesota Press.

Waquant, L. (2004). Body \& soul: Notebooks of an apprentice boxer. New York: Oxford University Press.

Witkowski, E. (2012). Inside the huddle: The phenomenology and sociology of team play in networked computer games. Ph.D. Thesis, IT University of Copenhagen, DK.

Witkowski, E. (2019). Counter-strike: Spectatorship. In N. Huntemann, \& M. Payne (Eds.), How to play videogames. New York: NYU Press.

Witkowski, E., \& Manning, J. (forthcoming). Player power: Networked careers in esports and high performance game livestreaming practices. Convergence.

Zelditch, M. (1962). Some methodological problems of field studies. American Journal of Sociology, 67(5), 566-576.

Aarseth, E. (2003). Playing research: Methodological approaches to game analysis. Retrieved from: http:// www.spilforskning.dk/gameapproaches/GameApproaches2.pdf

\section{Endnotes}

1 Revenue-generating esports refers to direct profit from the media sport through major financial sponsorship, broadcast rights, and in-game spectator-monetization. Non-revenue generating esports refers to community-oriented events with material sponsorship, such as peripherals or a small purse.

2 Though, significant shifts are currently taking place across embeddedness in the space of higher education.

3 https://esportsobserver.com/kespa-certifies-49-pc-bangs-official-eSports-facilities/

4 http://www.igea.net/wp-content/uploads/2017/07/Digital-Australia-2018-DA18-Final-1.pdf

5 Something might also be said of the missing strata of the "virtuoso" team/player--where a higher degree of expertise is reached through specific configurations of team participants who create another 
level of form and performance together, which is not innovative (i.e., new tactics), but rather has an enhanced attunement to intercorporeality, inter-team embodiments, and interplay.

6 Excellent work on team and progress raiding guilds, the coordination of expert play, and communication are prevalent in game studies and are foundational to this research. This study, however, explores the upper-level of expertise (virtuosic), and professionalized inter-team dynamics within a developing media sports culture.

7 A fascinating part of the networked media sports LAN sensorium comes from the incorporation of shoutcaster (live commentator) calls from the stage. BlizzCon winner "Quartzy" tells me that, after a win, he heard the shoutcaster call a cool-down used by his opponent. It was a piece of information which he did not register during play, though it was something which led him to act immediately, and, with that additional knowledge, this opened an opportunity for the team to attack.

8 Players across esports and media sports do talk of "instantly knowing" certain teammates. This is certainly not an unusual comment (having a good connection and similar play style), but as Atlas goes on to say, "instant knowing" gets more thorny when more people are involved.

9 I shared my surprise with a sports phenomenologist on this quick "accord" I experienced on the LAN scene with the young (mostly male) players. He suggested that it was perhaps exactly my positionality as an interested and connected-via sports-mature woman that these young men responded to in regard to their serious engagements because they had possibly never talked (let alone been asked) about their practice and excitement for their expert game performances before (Carless, personal communication, June 8, 2010).

10 Several players in this study were in direct contact with Blizzard on PvP abilities, and the Blizzard esports team members were constant observers of the tournament play of these expert participants.

Emma Witkowski

RMIT University

School of Design

emma.witkowski@rmit.edu.au 